\title{
STUDY OF A HYDROFLUIDIZATION SYSTEM USING COMPUTATIONAL FLUID DYNAMICS AND A DISCRETE ELEMENT METHOD I: FLOW FIELD AND VELOCITY PROFILES
}

\author{
J. D. ORONÁ, S. E. ZORRILLA and J. M. PERALTA
}

Instituto de Desarrollo Tecnológico para la Industria Química (INTEC). Universidad Nacional del Litoral - CONICET. Güemes 3450, S3000GLN. Santa Fe. Argentina.

E-mail: jmperalta@intec.unl.edu.ar

\begin{abstract}
Hydrofluidization (HF) is a method of chilling and freezing of foods that pumps a refrigerating liquid upwards through orifices into a vessel creating submerged jets and thus results in extremely high surface transfer phenomena. The objective was to model the flow field and the velocity profiles of spheres in a HF system using computational fluid dynamics and a discrete element method. The HF system consisted in a cylindrical vessel of $100-\mathrm{mm}$ diameter and $100-\mathrm{mm}$ height and a perforated plate with orifices of 3- $\mathrm{mm}$ diameter. The samples were 13 potato spheres of $10-\mathrm{mm}$ diameter. The operative variables were temperature $\left(-5^{\circ} \mathrm{C},-10^{\circ} \mathrm{C}\right)$, distance among the orifices $(10 \mathrm{~mm}, 20 \mathrm{~mm})$ and average velocity of the fluid at the orifices $(0.59 \mathrm{~m} / \mathrm{s}, 1.18 \mathrm{~m} / \mathrm{s})$. The results are promising to obtain relevant information about the momentum transfer and the dynamics of samples being processed within a HF system.
\end{abstract}

\section{INTRODUCTION}

Hydrofluidization (HF) is a method of chilling and freezing of foods that pumps a refrigerating liquid upwards through orifices into a vessel creating submerged jets and thus results in extremely high surface transfer phenomena (Fikiin, 1992; Peralta et al., 2012). Under controlled conditions, it represents an attractive industrial method with advantages related to the small equipment used and the improvement of the freezing of individual pieces of food, besides the advantages related to the immersion chilling and freezing process (ICF).

Several experimental (Verboven et al., 2003; Peralta et al., 2009) and theoretical (Peralta et al., 2010; 2012; Belis et al., 2012; 2013; 2014) studies on HF were conducted using different operative and geometric configurations. Those studies showed the effects of flow rate, refrigerant temperature, number of orifices, orifice arrangement, orifice-sample distance, orifice-orifice distance and sample-sample distance (Peralta et al., 2012; Belis et al., 2012 ; 2013; 2014) on the heat, momentum and mass transfer within the system. As a result, a better understanding of the relationship between the operative variables and the transport phenomena in simple HF configurations was obtained. However, in most of these studies, food samples were static single spheres impinged by single jets. Although those studies are useful as a first approach, their simplified nature limited the description capability of the methods used and consequently, the information of the transport phenomena involved. Thus, studies with several food samples are necessary. 
To take into account the moving nature of the food samples in a HF system, a method for modeling moving objects in fluid systems is to combine computational fluid dynamics (CFD) (Fluent, 2011) with a discrete element method (DEM) (Cundall and Strack, 1979). A DEM consists in performing momentum balances for each particle to estimate the velocity and position within a domain. These balances take into account different interaction forces such as fluid-particle drag, particle-particle collisions, particle-wall collisions, etc. Some of these forces are also balanced with the fluid movement solved through Navier-Stokes and continuity balances (Fluent, 2011). The main advantages of this technique is that relatively good predictions can be made using low computational efforts compared to systems were fluid to particle interactions (SFI) with moving meshes are used (Fluent, 2011). However, it is important to mention that the heat transfer due to particle-particle collisions are not estimated (Fluent, 2011).

The objective of this work was to model the flow field and the velocity profiles of spheres in a HF system using computational fluid dynamics and a discrete element method. The heat transfer and the turbulence intensity are studied in a companion paper (Part II) (Oroná et al., 2014).

\section{MATERIALS AND METHODS}

\subsection{Studied System and Conditions}

A hydrofluidization system consisted in a cylindrical vessel of $100-\mathrm{mm}$ diameter and $100-\mathrm{mm}$ height with a plate having different number of 3-mm diameter $(d)$ orifices at its base (Figure 1a) was studied. A square arrangement of 13 potato spheres of $10-\mathrm{mm}$ diameter $(D)$ placed initially at $3-\mathrm{cm}$ height $\left(H_{0}\right)$ was used as food product. The properties of potato (Solanum tuberosum L.) were used for the spheres and the liquid refrigerant was considered as an aqueous solution of $\mathrm{NaCl} 0.231 \mathrm{~kg} \mathrm{~kg}^{-1}(\mathrm{w} / \mathrm{w})$ (Peralta et al., 2012).

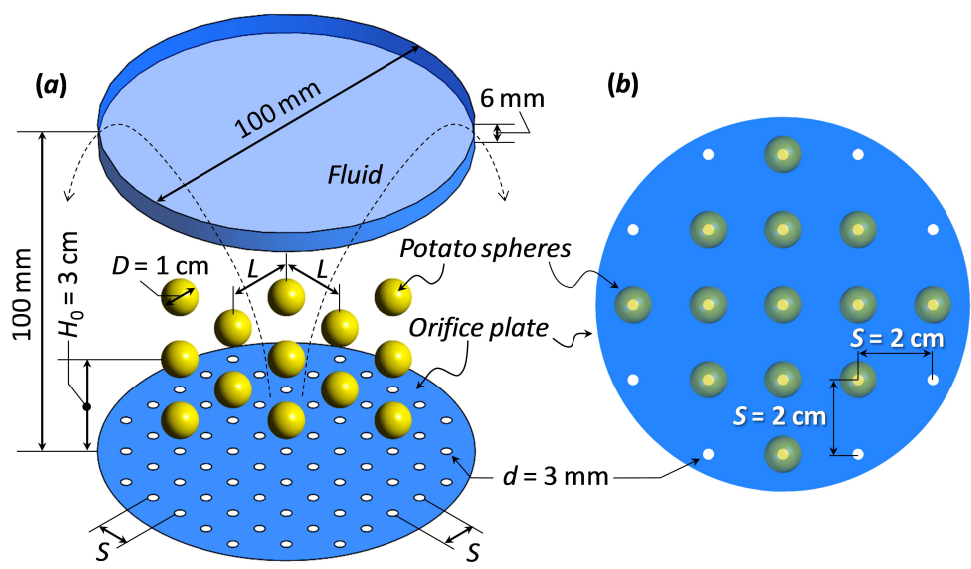

(c)

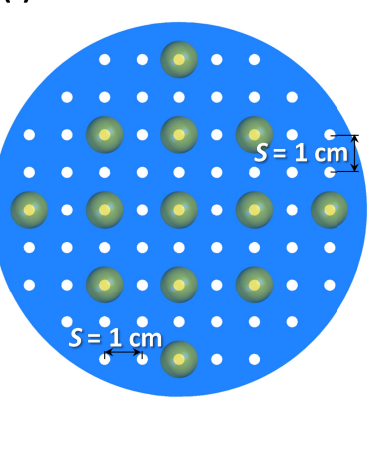

Figure $1-(a)$ Scheme of the studied HF system (physical domain) and arrangements (top view) used for the orifices and the spheres (initial). (b) $S=2 \mathrm{~cm}$ (21 orifices) and (c) $S=1 \mathrm{~cm}$ (69 orifices). $L=2 \mathrm{~cm}$.

Two square arrangements of round circles separated by a distance between their geometrical centers were used $(S=1 \mathrm{~cm}$ and $S=2 \mathrm{~cm}$ ) (Figure $1 b, c)$. The operative variables used were: refrigerant temperature $\left(T=-5^{\circ} \mathrm{C}\right.$ and $\left.T=-10^{\circ} \mathrm{C}\right)$ and the average fluid velocity at 
the orifices $\left(V=0.59 \mathrm{~m} \mathrm{~s}^{-1}\right.$ and $\left.V=1.18 \mathrm{~m} \mathrm{~s}^{-1}\right)$. A total of 8 conditions were used. These conditions were codified as follows: TxxVyyySz, where $\mathrm{xx}$ are the digits of $T$ (absolute value), yyy are the digits of $V$ (multiplied by 100) and $\mathrm{z}$ is the digit of $S$. For example: the code T10V059S2 means $T=-10^{\circ} \mathrm{C}, V=0.59 \mathrm{~m} \mathrm{~s}^{-1}$ and $S=2 \mathrm{~cm}$.

\subsection{Mathematical Modeling}

The flow field was modeled by solving mass (continuity) and momentum (Navier-Stokes) balances. The turbulence effect was estimated by the two parameter $\kappa-\omega$ Shear Stress Transport (SST) model (Fluent, 2011).

The relative movement of the spheres was considered taking into account the interactions between the fluid and the spheres, among spheres and between spheres and solid walls. These interactions were estimated through momentum balances for each sphere and structural data of the food. The sphere-fluid interactions were calculated by using a discrete phase method (DPM) and the sphere-sphere and sphere-wall interactions were estimated by using a discrete element method (DEM) (Fluent, 2011). The collisions were estimated taking into account elastic, viscous and friction effects (Fluent, 2011). A default set of the mechanical properties needed for the collisions of the spheres were used (Fluent, 2011).

\subsection{Computational Domain and Analyzed Variables}

The computational domain was similar to the physical domain. The main assumptions were those proposed by Peralta et al. (2010). A 6-mm slit at the top of the cylindrical wall was used as a fluid exit (Figure 1). Solid walls were assumed to be adiabatic and the system pressure was $0.1 \mathrm{MPa}$. A $1 / 7$ th power velocity profile was used in the round orifice because a fully turbulent liquid-jet with a turbulence intensity of $5 \%$ was assumed.

A mesh composed by tetrahedral elements was used to discretize the computational domain. This mesh was denser near the orifices.

Each condition was simulated up to $8 \mathrm{~s}$. In the first $3 \mathrm{~s}$, only the momentum and mass balances in the fluid were simulated to reach steady state conditions in the flow field. After $t=$ $3 \mathrm{~s}$, the spheres were injected and the following $5 \mathrm{~s}$ were used to simulate their movements and interactions inside the domain.

The momentum and mass balances for the fluid and the spheres (Navier-Stokes, continuity, DPM and DEM) were solved using the commercial CFD software ANSYS-ICEM-CFD 14.1 and ANSYS-FLUENT 14.1 (ANSYS Inc., Canonsburg, USA). The simulations were carried out using a PC with an Intel core i7 3930 processor of $3.2 \mathrm{GHz}$ with $16 \mathrm{~GB}$ of RAM (DDR3 $1600 \mathrm{MHz}$ ). Each simulation took approximately $90 \mathrm{~h}$ to converge.

Representative variables were used to study the flow field and spheres velocities. These variables were the volume-averaged sphere velocity $\left\langle v_{p}\right\rangle$ (Equation (1)) and the volume-averaged slip velocity $\left\langle v_{\text {slip }}\right\rangle$ (Equation (2)).

$$
\left\langle v_{p}\right\rangle=V_{T}^{-1} \int_{V_{T}}\left|\underline{v}_{p}\right| d V
$$




$$
\left\langle v_{s l i p}\right\rangle=V_{T}^{-1} \int_{V_{T}} v_{s l i p} d V=V_{T}^{-1} \int_{V_{T}}\left|\underline{v}_{p}-\underline{v}_{f}\right| d V
$$

where $\left|\underline{v}_{p}\right|$ is the magnitude of the velocity vector of an sphere $\underline{v}_{p}\left[\mathrm{~m} \mathrm{~s}^{-1}\right], v_{s l i p}$ is the magnitude of the relative velocity to the fluid of an sphere $\left|\underline{v}_{p}-\underline{v}_{f}\right|\left[\mathrm{m} \mathrm{s}^{-1}\right], \underline{v}_{f}$ is the velocity vector of the fluid at the center position of an sphere $\left[\mathrm{m} \mathrm{s}^{-1}\right]$ and $V_{T}$ is the domain volume.

\subsection{Model Validation}

The mathematical model was partially validated using heat transfer data from Belis et al. (2012) for a similar HF configuration but using static spheres. This validation is shown in Part II (Oroná et al., 2014).

\section{RESULTS AND DISCUSSION}

\subsection{Independence Test}

A mesh independence test was carried out testing 6 different mesh compositions (from 86296 to 170770 tetrahedra) using profiles of $\left\langle v_{p}\right\rangle$ and $\left\langle v_{f}\right\rangle$ (i.e. area-averaged fluid velocity) at $t=3 \mathrm{~s}$ for the condition T5V118S1. Based on this procedure and taking into account heat transfer and turbulence intensity variables checked in Part II (Oroná et al., 2014), a mesh composed by 170770 tetrahedra was used for the simulations. It is important to mention that to minimize convergence problems, a mesh with elements of the same or greater size than the spheres were considered in the selection procedure (Fluent, 2011). Figure 2 shows the velocity profiles for the meshes checked.
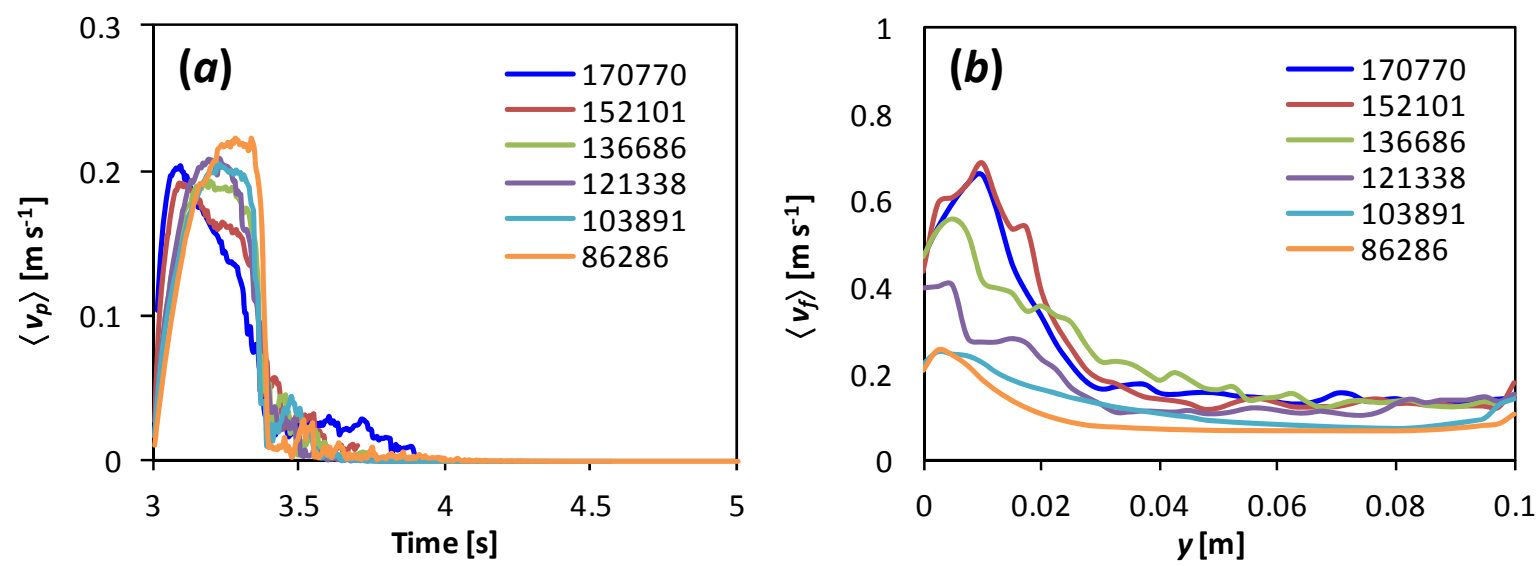

Figure 2 - Mesh independence. Local values of $(a)\left\langle v_{p}\right\rangle$ as a function of time and $(b)\left\langle v_{f}\right\rangle$ as a function of axial position for different mesh compositions.

\subsection{Velocity Contours and Streamlines}

Velocity contours with their respective streamlines for half of the conditions studied are shown in Figure 3. Only conditions with $T=-5^{\circ} \mathrm{C}$ are presented due to their similarity with 
their respective counterparts with $T=-10^{\circ} \mathrm{C}$. It is worth mentioning that Figure 3 shows fields evaluated at an arbitrary cut plane with the objective to represent the $3 \mathrm{D}$ information into a more easily observable 2D plane. These fields are evaluated at $t=3 \mathrm{~s}$ (immediately after the sphere injection).

In general, the velocity contours presented similar features to those observed by Belis et al. (2012), that is, an increase in the number of orifices produced greater local fluid velocities. This increment is more noticeable in the zones were jets are being developed. Streamlines show that, in general, fewer orifices produced larger interaction zones among jets and larger recirculation zones. The more affected jets were those near the domain axis. A possible explanation is that more orifices may produce less perturbed jet cores and consequently higher local velocities and less perturbed currents. Conversely, fewer orifices produce a less intense and more cyclic current due to the interaction among jets and between jets and low local fluid velocity zones. It is important to mention that periodic eddy formation and dissipation are observed.

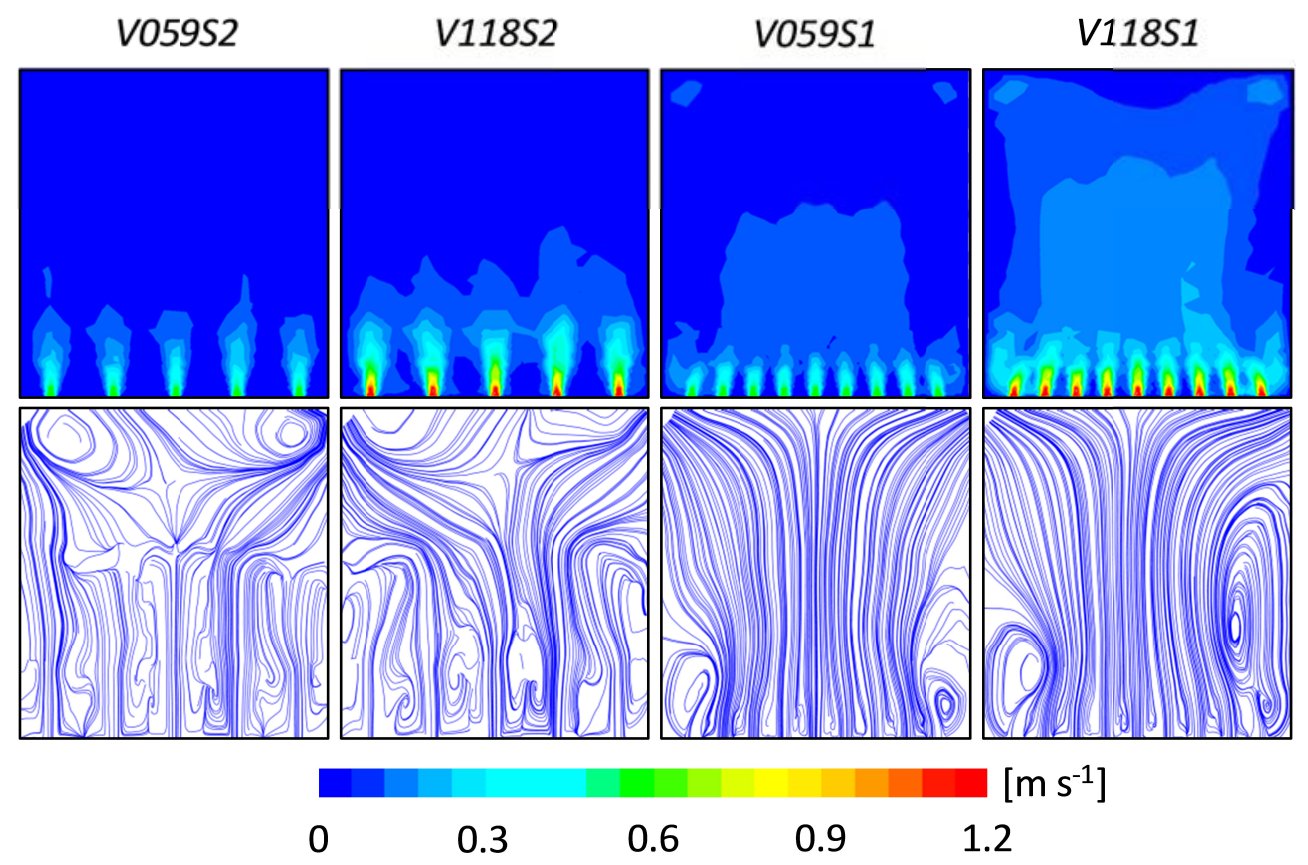

Figure 3 - Velocity contours and streamlines for selected conditions evaluated at $t=3 \mathrm{~s}$.

\subsection{General Behavior of the Spheres}

Figure 4 shows the behavior and the trajectories of the spheres as a function of time after being injected for selected conditions. Only cases with $T=-10^{\circ} \mathrm{C}$ are shown due to the negligible effect of temperature on the mobility of the spheres. In general and after being injected, the spheres started to continuously ascend at different velocities according to their initial radial position. The fastest spheres were those initially placed at the axis of the domain and the slowest were those ascending near the domain walls (some of these were slowed down due to large eddies observed in Figure 3). This behavior is the result of the velocity profile observed for the refrigerant. All the spheres finished their ascending at the liquid-air interface approximately $1.5 \mathrm{~s}$ after being injected, and in approximately the same initial radial position. 


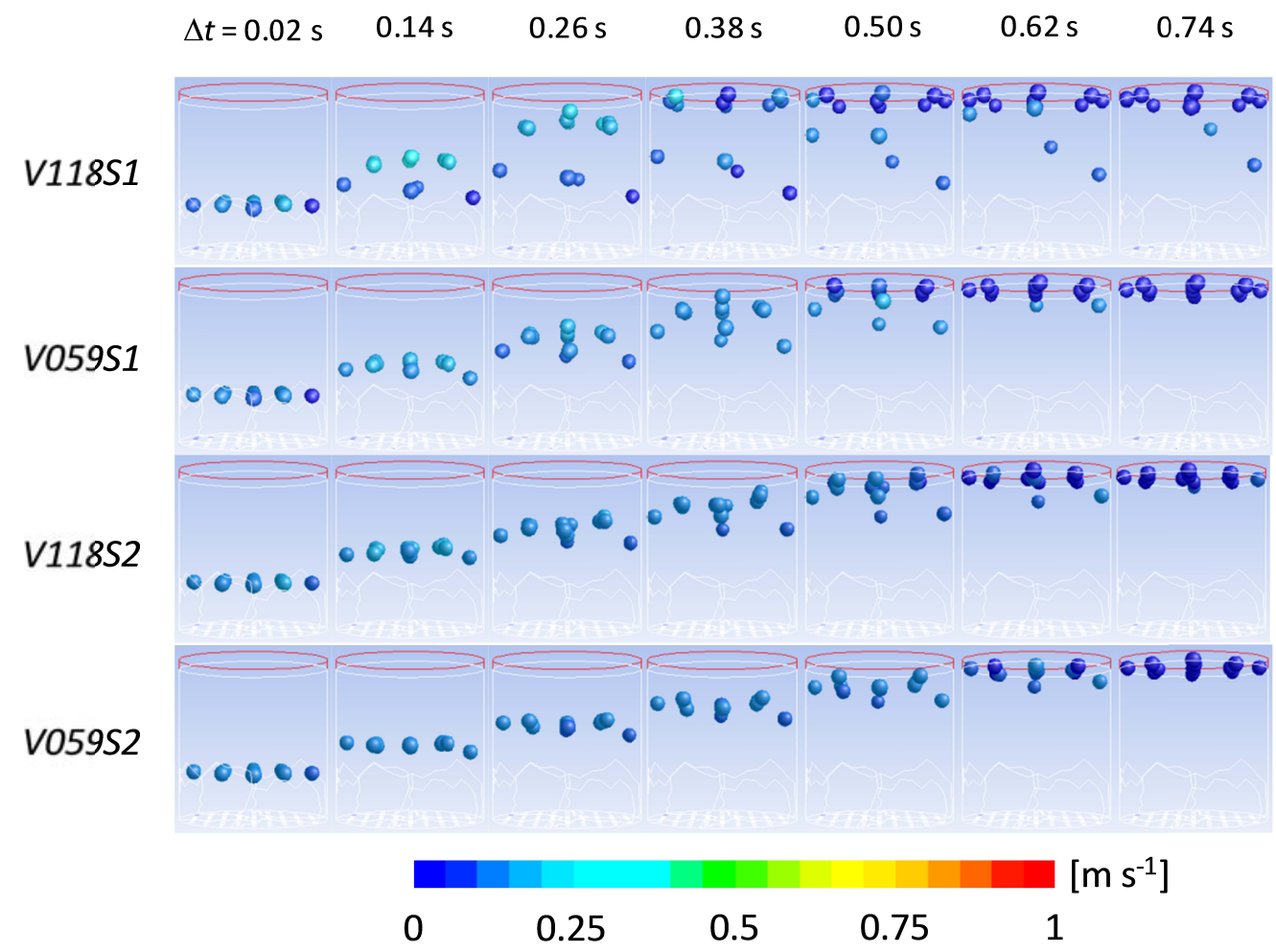

Figure $4-$ Behavior of the spheres for selected conditions $\left(T=-10^{\circ} \mathrm{C}\right)$. The color of the spheres represents their local absolute velocity.

\subsection{Averaged Absolute and Relative (Slip) Velocities of the Spheres}

Volume-averaged sphere velocity (Equation (1)) profiles as a function of time for the studied conditions are shown in Figure $5 a$. In general, the $\left\langle v_{p}\right\rangle$ profiles presented an initial increase up to a maximum point due to the initial acceleration produced by the contact with the refrigerant. Then, an approximately constant reduction or plateau was observed due to the momentum balance between spheres and fluid. Finally, a subsequent reduction to zero velocity values is obtained when the spheres reach the liquid-air interface.

The $\left\langle v_{p}\right\rangle$ profiles were mainly influenced by the number of orifices, the area-averaged fluid velocity at the orifices and marginally by the temperature. In generall, an increment in $S$ and a decrease in $V$ and $T$, produced a decrease in $\left\langle v_{p}\right\rangle$. Lower values of $S$ produce larger zones with high local fluid velocities generating higher maximum values and less marked descents in $\left\langle v_{p}\right\rangle$ profiles. An increment in $V$ leads to a slight increase in the maximum value and a shorter constant velocity period afterwards due to the shorter residence time of the spheres in the domain.

The volume-averaged relative velocity $\left\langle v_{\text {slip }}\right\rangle$ (Equation (2)) profiles as a function of time are shown in Figure $5 b$. In general, these profiles presented an initial velocity equal to the fluid velocity at the injection point of the spheres. This is due to the zero injection velocity initially applied to the spheres. A subsequent decrease was observed due to an initial velocity increment of the spheres and a slight decrease of the fluid velocity detected by the spheres as they ascend inside the domain. Then, a minimum is obtained when $\left\langle v_{p}\right\rangle$ and $\left\langle v_{f}\right\rangle$ are equaled. A 
zero value is obtained at this minimum but is not shown in Figure $5 b$ due to the time discretization used to show the results. Then, a second maximum value is observed when (and where) a maximum value of $\left\langle v_{p}\right\rangle$ is obtained. Later, a plateau or a slight decrease is observed similarly to the $\left\langle v_{p}\right\rangle$ profiles (Figure $5 a$ ) due to the small values of $\left\langle v_{f}\right\rangle$. Finally, a value of $\left\langle v_{s l i p}\right\rangle$ equal to $\left\langle v_{f}\right\rangle$ is obtained due to the spheres reached the liquid-air interface and $\left\langle v_{p}\right\rangle=0$. For cases with $V=1.18 \mathrm{~m} \mathrm{~s}^{-1}$ and $S=1 \mathrm{~cm}$, higher final values of $\left\langle v_{\text {slip }}\right\rangle$ are obtained, possibly due to the synergic effect of $V$ and $S$ on $\left\langle v_{f}\right\rangle$. Finally, the effect of the operational variables on $\left\langle v_{\text {slip }}\right\rangle$ was similar to that observed for $\left\langle v_{p}\right\rangle$ (Figure $5 a$ ). In general, an increment in $S$ and a decrease in $V$ and $T$ (marginal effect), produced a decrease in $\left\langle v_{\text {slip }}\right\rangle$.
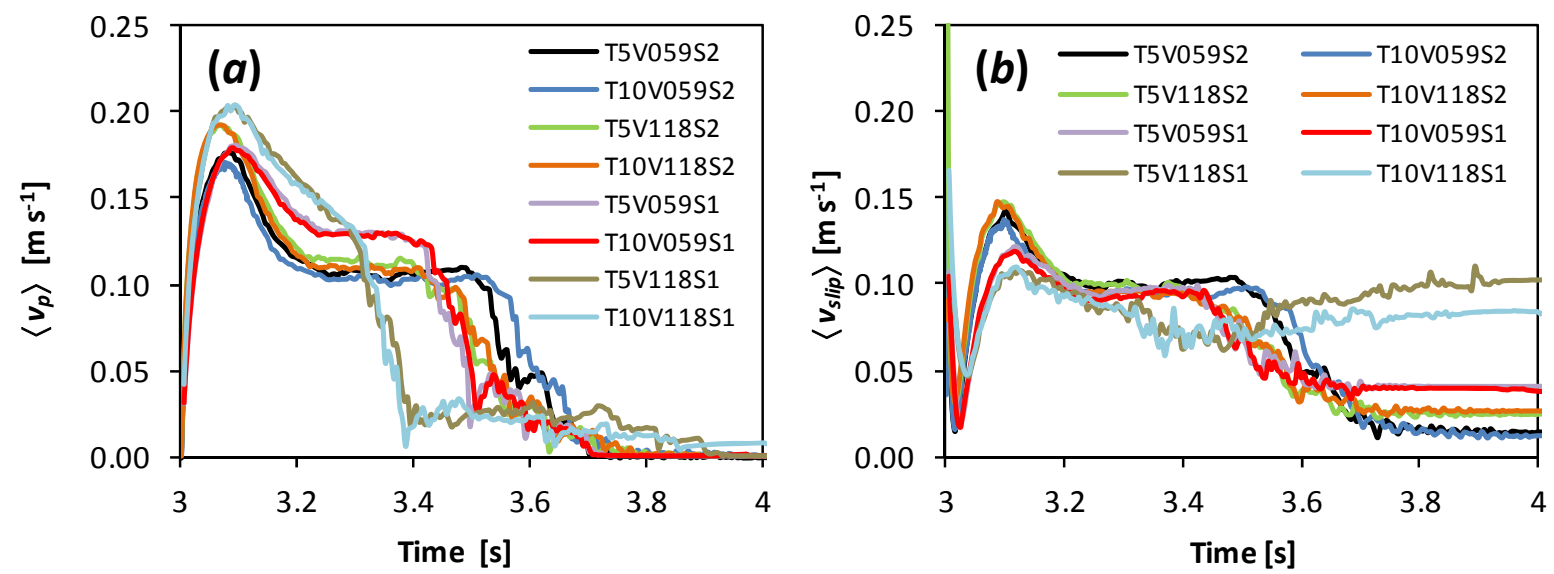

Figure 5 - Profiles of $(a)\left\langle v_{p}\right\rangle$ and $(b)\left\langle v_{\text {slip }}\right\rangle$ as a function of time for the studied conditions.

\section{CONCLUSIONS}

A study of the effect of operational variables (flow rate and temperature) and the number of orifices, on the transfer of momentum and mass that occur between moving spheres and the refrigerant in a HF system was performed. It was carried out using a mathematical model that solved Navier-Stokes and continuity with CFD and the mobility of spheres using discrete phase (DPM) and discrete element methods (DEM). Representative variables such as velocity contours and streamlines for the fluid and absolute and relative velocity profiles for the spheres were used to study the transfers. In general, $S$ was the most significant parameter followed by $V$. The refrigerant temperature had a marginal effect on the studied transfers.

This study, along with Part II, shows that the combination of CFD with DPM and DEM can be a powerful tool to simulate and study real HF systems with a minimum computational requirement compared to other approaches such as solid-fluid interaction studies.

\section{REFERENCES}

BELIS, E. E.; ZORRILLA, S. E.; PERALTA, J. M. Fenómenos de transporte en un sistema de hidrofluidización afectado por el número de orificios y las variables operativas. In: IV Congreso Internacional de Ciencia y Tecnología de los Alimentos (CICYTAC 2012), Nov. 14-16, Córdoba, Argentina, 2012. 
BELIS, E. E.; ZORRILLA, S. E.; PERALTA, J. M. Efecto del número de esferas estáticas de alimento y de orificios en la transferencia de energía en un sistema de hidrofluidización. In: XIV Congreso Argentino de Ciencia y Tecnología de los Alimentos (CYTAL), Oct. 23-25, Rosario, Argentina, 2013.

BELIS, E. E.; ZORRILlA, S. E.; PERALTA, J. M. Heat and mass transfer in a hydrofluidization system with multiple spheres. In: IFT14 Annual meeting and food expo, Jun. 21-24, New Orleans, USA, 2014.

CUNDALL, P. A.; STRACK, D. L. A discrete numerical model for granular assemblies. Géotechnique, v. 29, p. 47-65, 1979.

FIKIIN, A. G. New method and fluidized water system for intensive chilling and freezing of fish. Food Control, v. 3, p. 153-160. 1992.

FLUENT. Theory guide. ANSYS-FLUENT 14.1. Canonsburg: ANSYS Inc., 2011.

ORONÁ, J. D.; ZORRILLA, S. E.; PERALTA, J. M. Study of a hydrofluidization system using computational fluid dynamics and a discrete element method II: heat transfer and turbulence. In: XX Congresso Brasileiro de Engenharia Química (COBEQ), Oct. 19-22, Florianópolis, Brazil, 2014.

PERAlTA, J. M.; RUBIOLO, A. C.; ZORRILlA, S. E. Design and construction of a hydrofluidization system. Study of the heat transfer on a stationary sphere. J. Food Eng., v. 90, p. 358-364, 2009.

PERALTA, J. M.; RUBIOLO, A. C.; ZORRILLA, S. E. Mathematical modeling of the heat transfer and flow field of liquid refrigerants in a hydrofluidization system with a stationary sphere. J. Food Eng., v. 99, p. 303-313, 2010.

PERALTA, J. M.; RUBIOLO, A. C.; ZORRILLA, S. E. Mathematical modeling of the heat and mass transfer in a stationary potato sphere impinged by a single round liquid jet in a hydrofluidization system. J. Food Eng., v. 109, p. 501-512, 2012.

VERBOVEN, P.; SCHEERLINCK, N.; NICOLAÏ, B. M. Surface heat transfer coefficients to stationary spherical particles in an experimental unit for hydrofluidisation freezing of individual foods. Int. J. Refrig., v. 26, 328-336, 2003.

\section{Acknowledgments}

This research was supported partially by Universidad Nacional del Litoral (Santa Fe, Argentina), Consejo Nacional de Investigaciones Científicas y Técnicas (CONICET), and Agencia Nacional de Promoción Científica y Tecnológica (ANPCyT). 